\title{
Design and Development of a Water Quality Monitoring System by Using IoT
}

\author{
S.Sai Kumar ${ }^{1}$, B.V.Subba Rao $^{2}$, J.Rajendra Prasad $^{3}$ \\ ${ }^{1}$ Assistant Professor, Dept. of IT, P.V.P.Siddhartha Institute of Technology, India, saikumar.senagavarapu@gmail.com \\ ${ }^{2}$ Professor \& HOD, Dept. of IT, P.V.P. Siddhartha Institute of Technology, India, bvsrau@gmail.com \\ ${ }^{3}$ Professor, Dept. of IT, P.V.P. Siddhartha Institute of Technology, India, rp.rajendra@ rediffmail.com
}

\begin{abstract}
The conventional method of testing water quality is to gather samples of water manually and send to the lab to test and analyze. This method is time consuming, wastage of man power and not economical. The water quality measuring system that we have implemented checks the quality of water in real time through various sensors (one for each parameter: $\mathrm{pH}$, conductivity, temperature, turbidity) to measure the quality of water. As a variation in the value of this parameter points towards the presence of pollutants. The Wi-Fi module in the system transfers data collected by the sensors to the microcontroller, and transfers the data to the smart phone/PC. This system can keep a strict check on the pollution of the water resources and be able to provide an environment for safe drinking water.
\end{abstract}

Key words: IoT, pH, Conductivity, Temperature, Turbidity

\section{INTRODUCTION}

Now a days water is polluted due to the rapid increase in population and need to meet demands of human beings for agriculture, industrial and personal use. The quality of ground water is also affected by pesticides and insecticides. The rivers in India are getting polluted due to industrial waste and discharge of untreated sewage.In order to eliminate problems associated with manual water quality monitoring, CPCB has planned to go hi-tech and plans to establish 'Real Time Water Quality Monitoring (WQM) Network' across Ganga Basin. Stephen Brosnan, 2007 investigated a wireless sensor network (WSN) to collect real time water quality parameters (WQP). Quio Tie-Zhn, 2010 developed online water quality monitoring system based on GPRS/GSM. The information was sent by means of GPRS network, which helped to check remotely the WQP. Kamal Alameh, 2011presented web based WSN for monitoring water pollution using ZigBee and WiMAX networks. The system measured various WQP. It collected, processed measured data from sensors, and directed through ZigBee gateway to the web server by means of WiMAX network to monitor quality of water from large distances. System was capable of monitoring water pollution in real time. Dong He, 2012 developed WQM system based on WSN. The remote sensor was based on ZigBee network. WSN tested WQP and sent data to Internet using GPRS. With the help of Web, information was gathered at remote server. Kulkarni Amruta, 2013 created solar powered WQM utilizing remote sensor network. The Base station (BS) gathered information from distant remote sensors. The BS associated with ZigBee module was powered by sunlight baseboard[1],[2],[3],[4],[5],[6],[7].
In the existing system the equipment cost is very high and it takes lots of time to process. Traditional methods have the disadvantages like complicated methodology, long waiting time for the results, low measurement precision and high cost. So with the implementation in the technology, we use different methods and techniques to check quality of water.

\section{DISADVANTAGES}

The following are the disadvantages of existing system:

- High complexity: The existing system has the less complexity like complicated methodologies and low measurement precisions.

- High cost: Cost of the system depends on number of parameters to be measured. In the existing system the equipment cost is very high so the normal people may not adopt the system.

- Less accuracy: when compared with the proposed system, the accuracy level is high in the existing system because the proposed system consisting of many sensors and it is equipped in easy way.

- Consumes more time: Water quality monitoring systems need to quickly identify any changes in the quality of water and report the same to the officials for immediate action. In the existing system it consumes more time.

\section{Proposed Work}

In this proposed system, the complexity reduces and the performance increases by collecting the data of the water parameters such as temperature, co2, ph, water level. Water is one of the most essential natural resource that has been gifted to the mankind. But the rapid development of the society and numerous human activities speeded up the contamination and deteriorated the water resources. For above water quality monitoring is necessary to identify any changes in water quality parameters from time-to time to make sure its safety in real time. The Central Pollution Control Board (CPCB) has established a series of monitoring stations on water bodies across the country which monitor the water quality on either monthly or yearly basis. This is done to ensure that the water quality is being maintained or restored at desired level. It is important that it is monitored on regular basis. Water quality monitoring helps in evaluating the nature and extent of pollution control required, and effectiveness of pollution control measures. CPCB has plans to establish water quality monitoring network across Ganga river basin. All the stations will operate in real time and central station can access data from any of the above stations using GPRS/GSM or 3Gcellular services. central station. Large amount of data can help to 
take right decisions and also to implement in time accordingly. Cost of the system depends on number of parameters to be measured. Water quality monitoring systems need to quickly identify any changes in the quality of water and report the same to the officials for immediate action. The system is designed for continuous onsite sensing and real time reporting of water quality data where the officials can access the data on the smart phone/PC through Internet. The below Figure 1 represents proposed architecture[8],[9],[10],[11],[12],[13],[14]

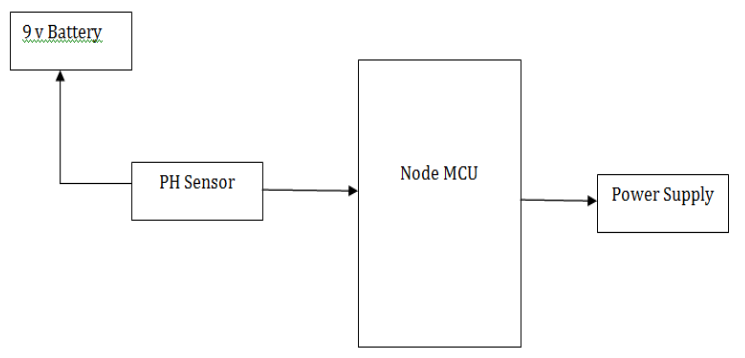

Figure 1: Proposed system of water quality monitoring system.

\section{ADVANTAGES}

The following are the advantages of proposed system:

- Multiple sensors: The proposed system consists of multiple sensors to measures the parameters like quality of the water, temperature of water, ph of the water and also measures the waterlevel.

- Consumes less time: This system consumes very less time to give the result. So that the r equired action is taken at the proper situation and within the time.

- Accuracy: the proposed system gives the accurate result when compared with the existing system as it consists of multiple sensors.

- Man power: This system requires less man power. As the technology is improved rapidly, people were opting for the systems with less man power and with high accuracy. This system consisting of less man power.

- Identifies the harmful impurities: It predicts ions present in the water. If the ph is high water is of good quality or less quality.

\section{IOT DEVICES}

The modules present in our project are:

\section{- PH SENSOR:}

$\mathrm{PH}$, commonly used for water measurements, is a measure of acidity and alkalinity, or the caustic and base present in a given solution. It is generally expressed with a numeric scale ranging from $0-14$. The value 7 represents neutrality. The numbers on the scale increase with increasing alkalinity, while the numbers on the scale decrease with increasing acidity. Each unit of change represents a tenfold change in acidity or alkalinity. The $\mathrm{pH}$ value is also equal to the negative logarithm of the hydrogen-ion concentration or hydrogen-ion activity. It consists of electric conductivity sensor embedded in it. The most common method of measuring $\mathrm{pH}$ is to use an electrochemical $\mathrm{pH}$ sensor. Combination $\mathrm{pH}$ sensors are a type of electrochemical $\mathrm{pH}$ sensor that feature both a measuring electrode and a reference electrode. A $\mathrm{pH}$ sensor helps to measure the acidity or alkalinity of the water with a value between 0-14.
When the $\mathrm{pH}$ value dips below seven, the water starts to become more acidic. Any number above seven equates to more alkaline. Each type of $\mathrm{pH}$ sensor works differently to measure the quality of the water. The $\mathrm{pH}$ of water can help determine the quality of water. Measuring the $\mathrm{pH}$ can also provide indications of pipe corrosion, solids accumulation, and other harmful byproducts of an industrial process. The below Figure 2 represents $\mathrm{Ph}$ Sensor.

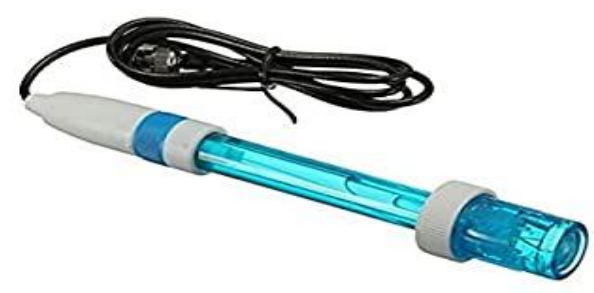

Figure 2: ph sensor

\section{- ARDUINO UNO R3:}

The Arduino Uno R3 is a microcontroller board based on a removable, dual-inline-package (DIP) ATmega328 AVR microcontroller. It has 20 digital input/output pins (of which 6 can be used as PWM outputs and 6 can be used as analog inputs). Programs can be loaded on to it from the easy-to-use Arduino computer program. The Arduino has an extensive support community, which makes it a very easy way to get started working with embedded electronics. The R3 is the third, and latest, revision of the Arduino Uno. It contains everything needed to support the microcontroller; simply connect it to a computer with a USB cable or power it with a AC-to-DC adapter or battery to get started.

The Uno differs from all preceding boards in that it does not use the FTDI USB-to-serial driver chip. Instead, it features an ATmega16U2 programmed as a USB-to-serial converter. This auxiliary microcontroller has its own USB boot loader, which allows advanced users to reprogram it. The below Figure 3 represents Arduino Board.

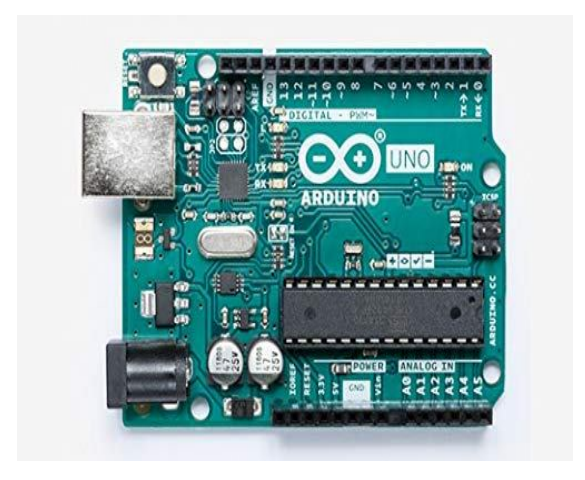

Figure 3: Arduino Uno R3

\section{- Node MCU:}

The All new Node MCU ESP8266 V3 Lau CH340 Wife Dev. Board is a fast leading edge low-cost Wife technology. Modern high-level mature LUA based technology. It is an 
integrated unit with all available resources on board. It is super simple to complement your existing Arduino projects or any development board that has $\mathrm{I} / \mathrm{O}$ pins available. Modern Internet development tools such as Node.js can take advantage the Node MCU with the built-in API to put your idea on the fast track immediately. Node MCU is built based on the mature ESP8266 technology to take advantage of the abundant resources available on the web.NodeMCU has ESP-12 based serial WiFi integrated on board to provide GPIO, PWM, ADC, I2C and 1-WIRE resources at your fingertips, built-in USB-TTL serial with super reliable industrial strength $\mathrm{CH} 340$ for superior stability on all supported platforms. This module is one of the cheapest available wifi-modules in the market. V3 or Version3 is the latest version of this module. This tutorial, however, will facilitate you to connect all the versions of ESP8266 NodeMcu, i.e V1, V2 or V3.

- Arduino-like hardware IO - Advanced API for hardware IO, which can dramatically reduce the redundant work for configuring and manipulating hardware. Code like Arduino, but interactively in Lua script.

- Nodejs style network API Event-driven API for network applications, which facilitates developers writing code running on a $5 \mathrm{~mm} 5 \mathrm{~mm}$ sized MCU in Nodejs style. Greatly speed up your IOT application developing process.

- Development Kit The Development Kit based on ESP8266, integrates GPIO, PWM, IIC, 1-Wire and ADC all on one board. Power your development in the fastest way combination with NodeMCU Firmware!

The NodeMcu is an open-source firmware and development kit that helps you to prototype your IoT product with few Lua script lines. The Development Kit based on ESP8266, integrated GPIO, PWM, IIC, 1- Wire and ADC all in one board. The below Figure 4 represents Node MCU.

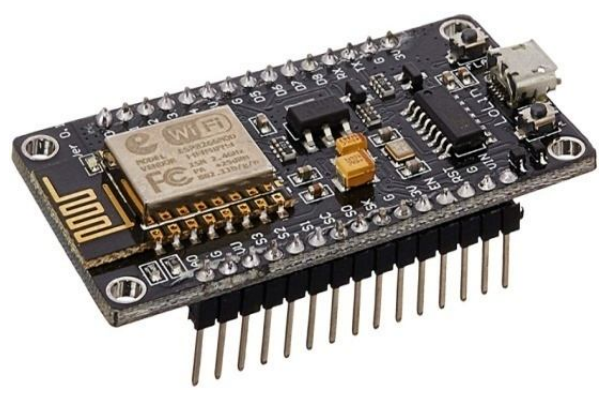

\section{- BLYNK APP:}

Figure 4:Node MCU

Blynk is a new platform that allows you to quickly build interfaces for controlling and monitoring your hardware projects from your iOS and Android device. After downloading the Blynk app, you can create a project dashboard and arrange buttons, sliders, graphs, and other widgets onto the screen. Using the widgets, you can turn pins on and off or display data from sensors. Whatever your project is, there are likely hundreds of tutorials that make the hardware part pretty easy, but building the software interface is still difficult. With Blynk, though, thesoftware side is even easier than the hardware. Blynk is perfect for interfacing with simple projects like monitoring the temperature of your fishtank or turning lights on and off remotely. Personally, we are using it to control water quality. Currently, Blynk supports most Arduino boards, Raspberry Pi models, the ESP8266, Particle Core, and a handful of other common microcontrollers and single-board computers, and more are being added over time. Arduino Wi-Fi and Ethernet shields are supported, though you can also control devices plugged into a computer's USB port as well.

\section{Create a Blynk Account}

After you download the Blynk App, you'll need to create a New Blynk account. This account is separate from the accounts used for the Blynk Forums, in case you already have one.We recommend using a real email address because it will simplify things later.

\section{Create a New Project:}

After you've successfully logged into your account, start by creating a new project.

\section{Choose Your Hardware:}

Select the hardware model you will use. Check out the list of supported hardware!

\section{Auth Token:}

Auth Token is a unique identifier which is needed to connect your hardware to your smartphone. Every new project you create will have its own Auth Token. You'll get Auth Token automatically on your email after project creation. You can also copy it manually. Click on devices section and selected required device

And you'll see token: It's very convenient to send it over e-mail. Press the e-mail button and the token will be sent to the e-mail address you used for registration. You can also tap on the Token line and it will be copied to the clipboard. Now press the "Create" button.

\section{- Add a Widget:}

Your project canvas is empty, let's add a button to control our LED.Tap anywhere on the canvas to open the widget box. All the available widgets are located here. Now pick a button.

Drag-n-Drop - Tap and hold the Widget to drag it to the new position.

Widget Settings - Each Widget has it's own settings. Tap on the widget to get to them.

The most important parameter to set is PIN . The list of pins reflects physical pins defined by your hardware. If your LED is connected to Digital Pin 8 - then select D8 (D stands for Digital).

\section{- Run the Project:}

When you are done with the Settings - press the PLAY button. This will switch you from EDIT mode to PLAY mode where you can interact with the hardware. While in PLAY mode, you won't be able to drag or set up new widgets, press STOP and get back to EDIT mode. You will get a message saying "Arduino UNO is offline". We'll deal with that in the next section. 


\section{- 9V Battery:}

This is General purpose 9V Original HW marked Non-Rechargeable Battery for all your project and application needs. As we experienced the use of this battery in our testing lab for various purpose, we can assure you the best quality, long life and genuineness of this battery among all options available in the market at this cost. With its Universal $9 \mathrm{~V}$ battery size and connecting points, it can be used in many DIY projects as well as household applications and they can easily be replaced and installed, the same as you would an AA battery or an AAA battery. Whether you need a new battery for your applications like a Flashlight, Portable Phone Charger, Wireless doorbell, Wireless audio transmitter-receiver systems or your kid's toys, etc. or even if you are looking for a long-lasting, reliable option for your sensor devices like a smoke detector, everyone needs a good 9-volt battery every once in a while. It's also a great idea to keep extra 9 volt batteries around in case of an emergency. That's why we've found one of the best 9-volt battery available.

Constant 9V Output till lasts Metal Jacket Body Good Built Quality and hence Leak proof .Easy to install and ReplaceCorrosion free Connector Point for long-term use $0 \%$ Mercury and Cadmium. Environment-friendlyOEM Compatible. The below Figure 5 represents 9V Battery.
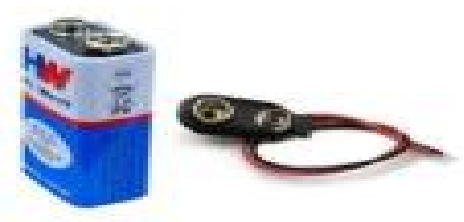

Figure 5 : 9V Battery

\section{RESULTS}

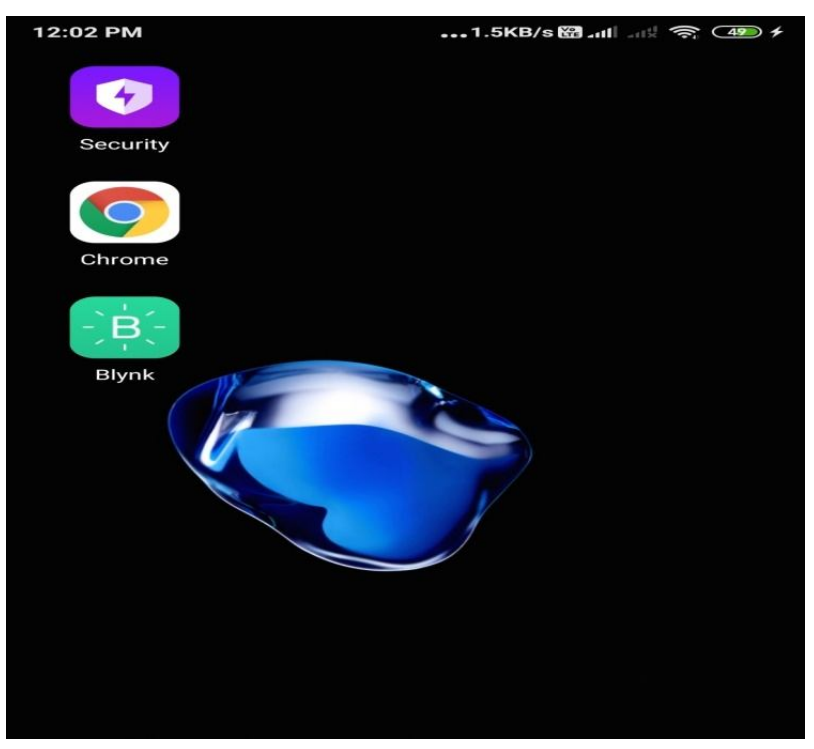

Description: Home page.

Installing Blink app in the Mobile Device/ Pc. The Figure Defines the Blink app Icon placed in the desktop.

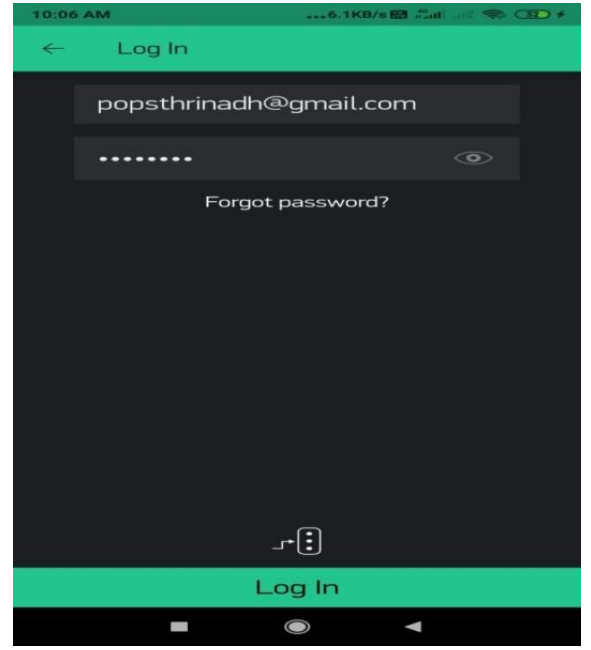

Description: Login screen.

The Figure indicated the after successful installation of the Blink app to create the Account to load the Project

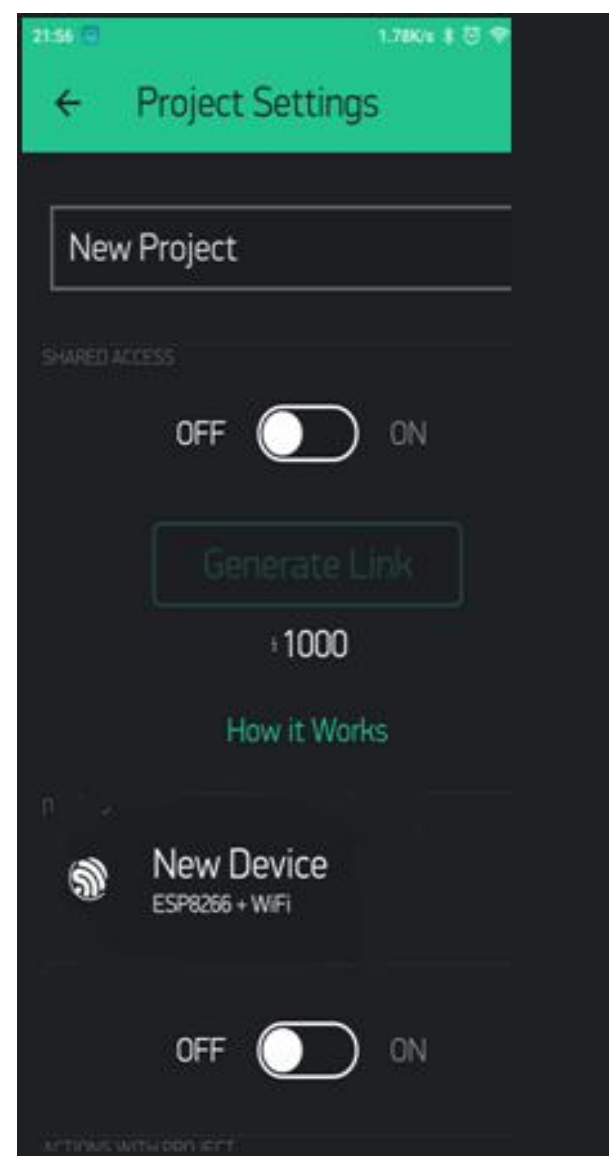

Description: Advanced ip scanner.

The Figure indicated the Project Creation in Blink app. 


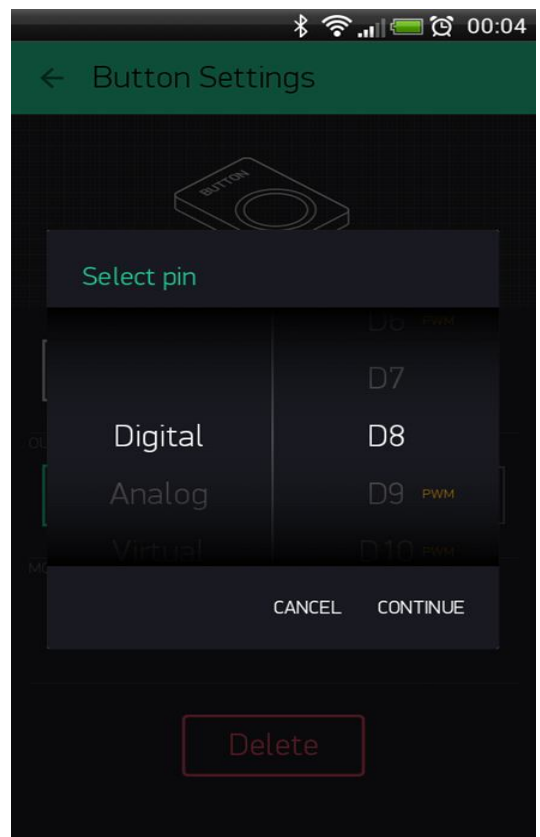

Description: Digital pin

The Figure indicated the creating the digital pin for security purpose for accessing the account in the Blink app.

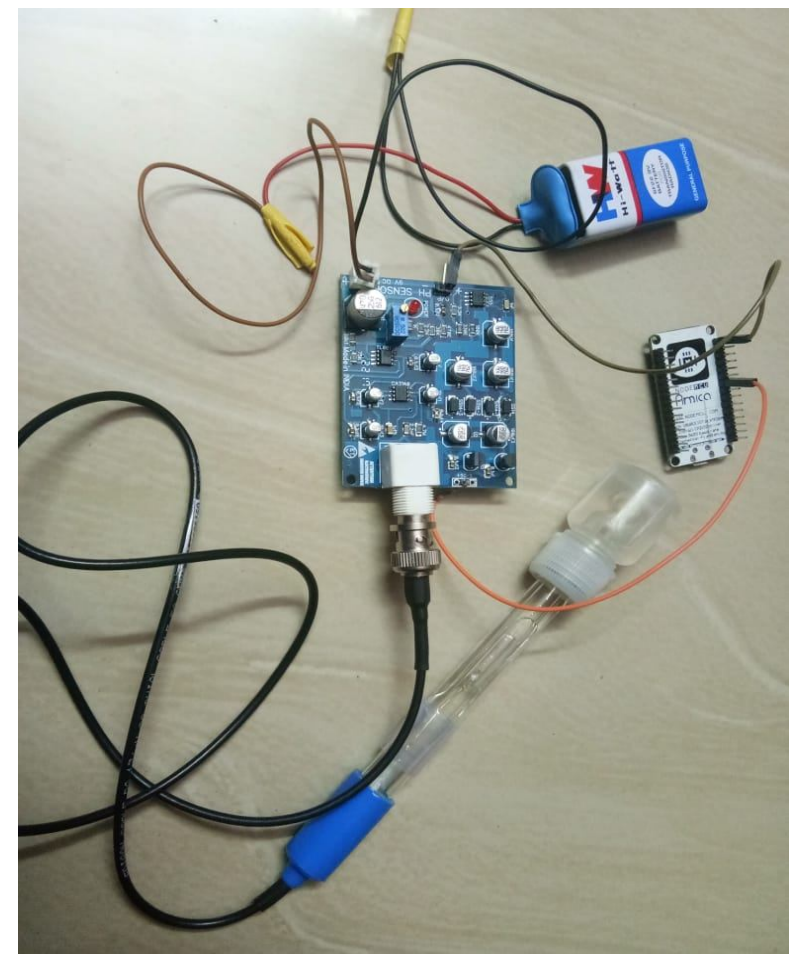

\section{Description: IoT kit}

The Figure indicated the IoT Kit connection between the Arduino board to $\mathrm{pH}$ sensor, Arduino board to Node MCU and Power supply.

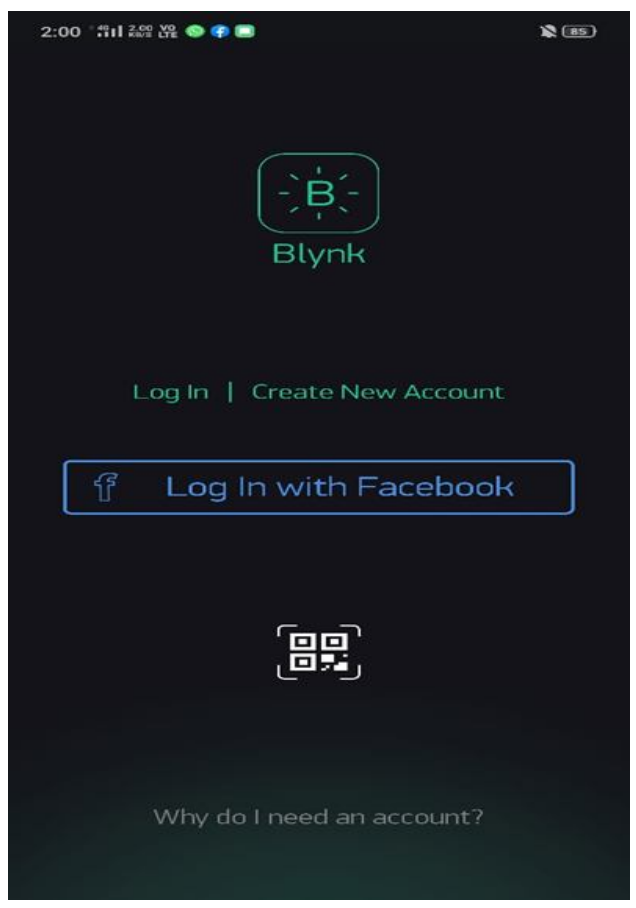

\section{Description: Home Screen}

The above Figure indicates the Home Screen in Blink app after successful login.

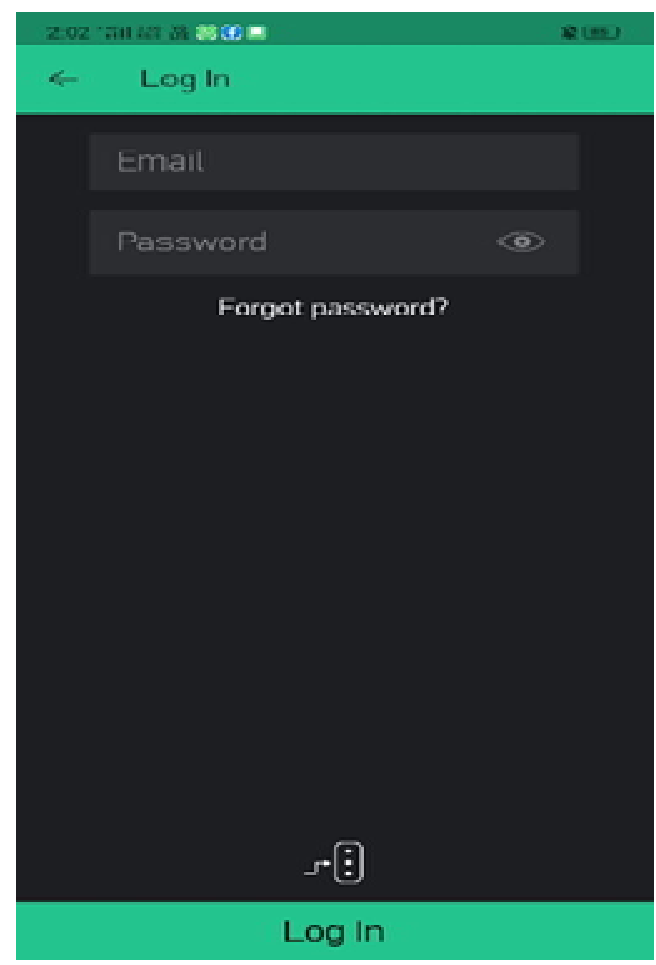

\section{Description: Login Screen}

The above Figure indicates the Login Screen in Blink app through mail id. 


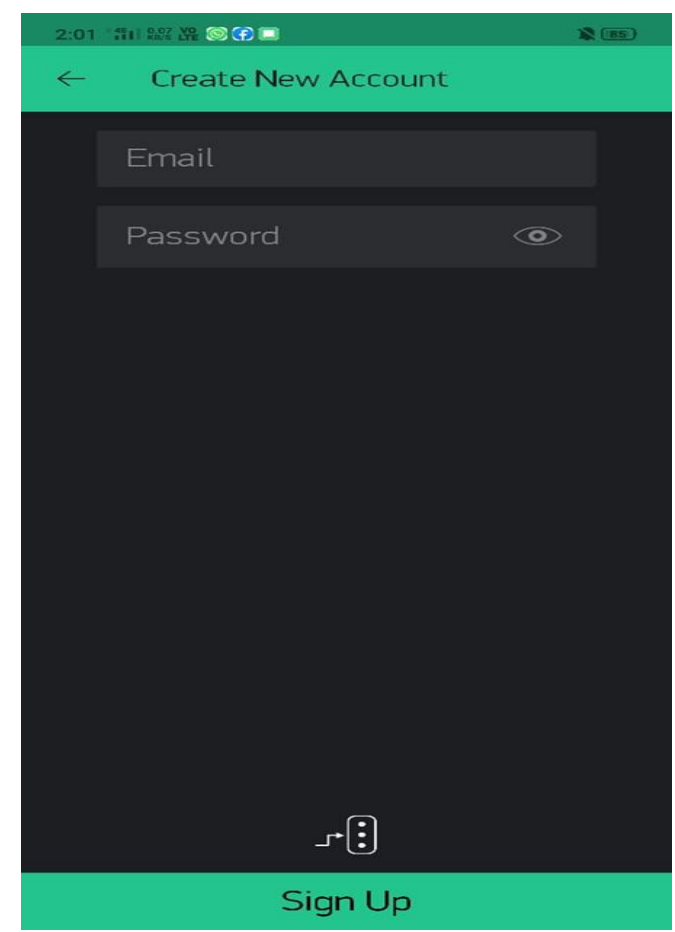

Description: sign up

The above Figure indicates the Creating new account in Blink app through mail id.

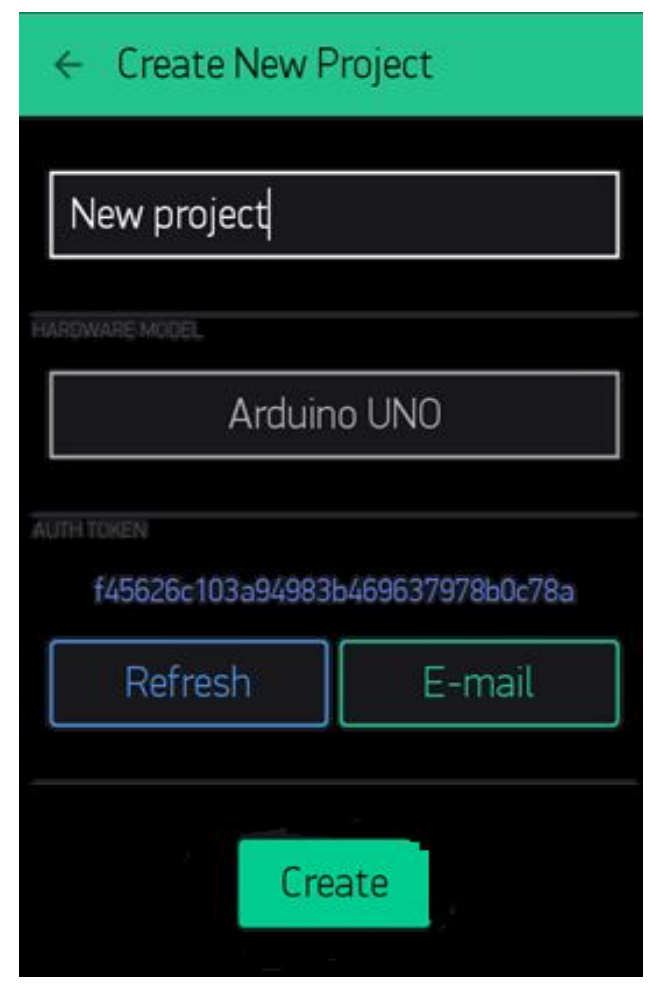

Description:create project.

The above Figure indicates the Creating new Project in Blink app through mail id.

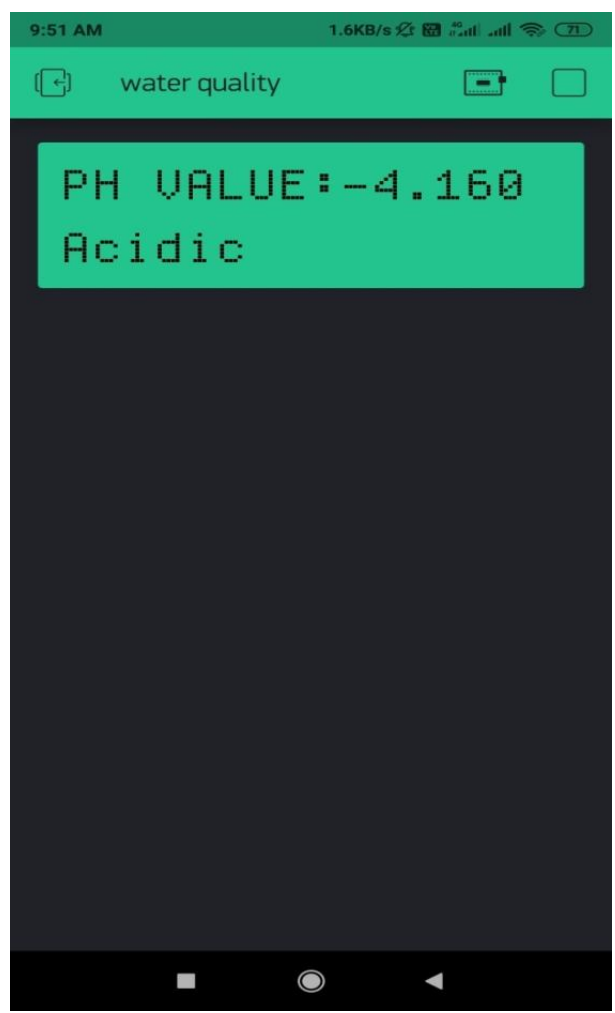

Figure 6:Output 1

The above Figure 6 indicates the after creating new Project the $\mathrm{pH}$ sensor identifies the water quality that value is present in the Blink app.

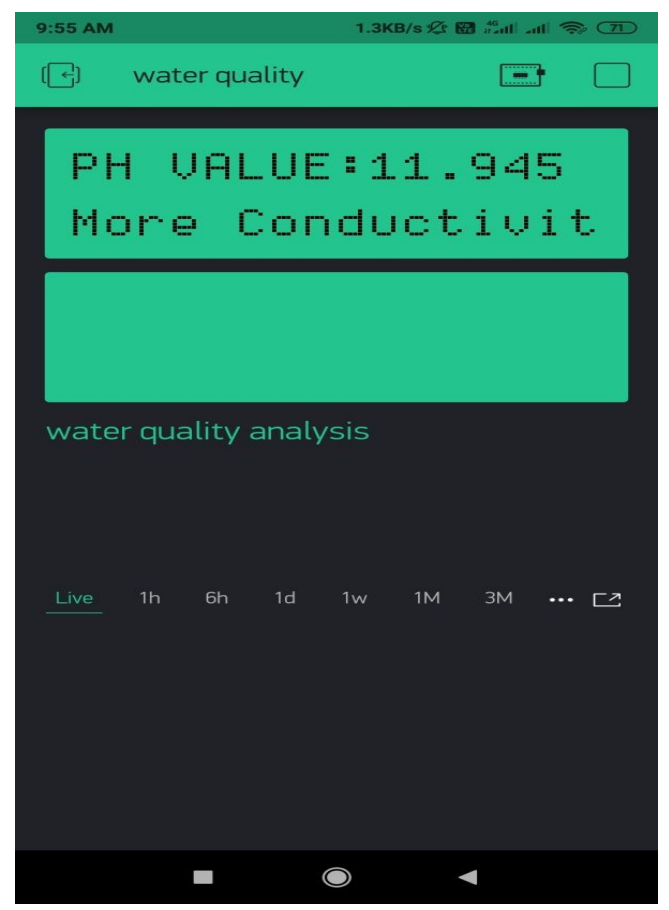

Figure 7:output 2

The above Figure 7 indicates that the $\mathrm{pH}$ sensor identifies the water quality that value more than the normal $\mathrm{pH}$ value which is more conductivity that information is also present in the Blink app. 


\section{CONCLUSION}

The future scope of this project is to add the more sensors and in the proposed system we implemented this water quality monitoring in real time. So control the Pollution of the water also control through IoT. By using the monitoring system we can easily prevent the wastage of water and the water will be save to our next generations. The further development of the system includes detecting the more parameters for most secure purpose. Increase the parameters by addition of multiple sensors. Detecting more chemicals or impurities present in the water along with the amount of chemicals or impurities present and displaying the message.

Monitoring of PH Water makes use of water detection sensor with unique advantage and existing GSM network. The system can monitor water quality automatically, and it is low in cost and does not require people on duty. So the water quality testing is likely to be more economical, convenient and fast. The system has good flexibility. Only by replacing the corresponding sensors and changing the relevant software programs, this system can be used to monitor other water quality parameters. The operation is simple. The system can be expanded to monitor hydrologic, air pollution, industrial and agricultural production and so on. It has widespread application and extension value. By keeping the embedded devices in the environment for monitoring enables self-protection (i.e., smart environment) to the environment. To implement this need to deploy the sensor devices in the environment for collecting the data and analysis. By deploying sensor devices in the environment, we can bring the environment into real life i.e. it can interact with other objects through the network. Then the collected data and analysis results will be available to the end user through the Wi-Fi or Node MCU.

\section{REFERENCES}

1 IOT Based Water Quality Monitoring System International Journal of Scientific Research in Computer Science, Engineering and Information Technology (C) 2018 IJSRCSEIT| Volume3 |Issue1| ISSN:2456-3307:1423-1428.

2 R.M. Bhardwaj," Overview of Ganga River Pollution", Report: Central Pollution Control Board, Delhi,2011

3 NivitYadav, "CPCB Realtime Water Quality Monitoring", Report: Center for Science and Environment, 2012

4 Tuan LeDinh, WenHu, Pavan Sikka, PeterCorke, L.Overs,Stephen Brosman, "Design and Deployment of a Remote Robust Sensor Network: Experiences from Outdoor Water", 32 ${ }^{\text {nd }}$ IEEEConf. On Local Computers, pp799-806,Feb.,2007

5 QuioTie-Zhn,SongLe, "The Design of Multi parameter Online Monitoring System of Water Quality based on GPRS", Report: Advanced Transducers and intelligent Control System Lab, Taiyuan Technical University, Taiyuan, China,2010
6 Steven Silva, Hoang NGhia Nguyen, Valentina, Tiporlini, Kamal Alameh, "Web based Water Quality Monitoring with Sensor Network: Employing ZigBee and WiMAX Technology", $36^{\text {th }}$ IEEE Conf. on Local Computer Networks, 2011

7 DongeHe,Li-XinZhang, "The Water Quality Monitoring System based on Wireless Sensor Network" Report: Mechanical and Electronic Information Institute, China University of Geo Science, WuHen, China, 2012

8 Pavlos Papa georgiou, "Literature Survey on Wireless Sensor Networks", Report: University of Maryland, 16July 2003

9 Satish Turken, Amruta Kulkarni, "Solar Powered Water Quality Monitoring System using Wireless Sensor Network", IEEE Conf. on Automation, Computing, communication, control, and compressed sensing, pp 281-285, 2013

10 LiangHu, FengWang, JinZhouandKuoZhao "A Survey from the Perspective of Evolutionary Process in the Internet of Things", International Journal of Distributed Sensor Networks, Article ID 462752, 2015

11 Thing Speak- Understanding your Things- The open IoT Platform with MATLAB analytics, Math Works.

12 User Manual Arm7-LPC2148 Development kit Pantech Solutions.

13 Jaspreet Kaur, Navpreet Kaur "Trust Based Technique for the Multicasting in IoT", International Journal of Emerging Trends in Engineering Research, Volume 8, Issue No.8, August 2020, ISSN 2347-3983,PP.4574-4579.

14 Anchal, Pooja Mittal 'IoT Based Intelligent Modeling of Smart Home Parking Environment", International Journal of Emerging Trends in Engineering Research, Volume 8, Issue No.7, July 2020, ISSN 2347-3983,PP.3442-3446. 